\title{
Atypical presentation and localization of granulosa cell tumor-A case report and review of the literature ${ }^{*}$
}

\author{
Evangelos Grigoriou Sakkas , Dario Bucella, Alexandre Roland De Wind, Claudia Stanciu, \\ Frederic Buxant \\ Ixelles Hospital (Centre Hospitalier, IRIS Sud), Free University of Brussels, Brussels, Belgium \\ Email: "
}

Received 9 February 2012; revised 5 March 2012; accepted 14 March 2012

\begin{abstract}
Introduction: Extraovarian granulosa cell tumor (GCT) is a very uncommon tumor, assumed to arise from the ectopic gonadal tissue along the embryonal route of the genital ridge. Case Report: We report the case of a 25 year-old woman who was presented at the emergency unit with a severe abdominal pain focused on the left iliac fossa. The patient had delivered normally 2 months before. An ovarian mass of $79 \times 67 \times 89 \mathrm{~mm}$ was shown in vaginal ultrasound as well as at the abdominal scan. Exploratory laparoscopy was performed and a torsion of the fallopian tube and an hematosalpinges was visualized. Re-vascularisation was not achieved and a left salpingectomy took place. The immuno-histopathology report revealed an extraovarian GCT deriving from the fimbriae of the tube. Follow-up surgery was discussed. The case is presented for its rarity.
\end{abstract}

Keywords: Extraovarian Granulosa Cell Tumor; Torsion

\section{INTRODUCTION}

Ovarian GCTs (Granulosa Cell Tumor) are uncommon neoplasms that arise from the sex-cord stromal cells of the ovary and they comprise $2 \%-5 \%$ of all ovarian cancers.

Rarely, GCT can develop at an extraovarian site, even in an oophorectomized patient. The primary extraovarian GCT is extremely rare tumor. In English literature from 1938 till today only 12 cases have been reported [1-9].

\section{CASE REPORT}

A 25 year-old patient, G1P1, presented in the emergency unit for an abdominal pain which in the beginning was

${ }^{*}$ Declaration of interest: the authors report no conflicts of interest. The authors alone are responsible for the content and the writing of the paper.

${ }^{\#}$ Corresponding author. diffuse but later on it was focused on the left iliac fossa accompanied by episodes of vomiting. Her personal history did not reveal anything apart the fact that she had delivered normally two months before and the delivery was followed by moderate bleeding. A hormonal intrauterine contraceptive device was inserted one month after delivery.

At her arrival the patient was afebrile, perspiring and very painful. The clinic exam revealed an elevated sensibility at the left iliac fossa and the palpation of a suprapubic mass. On investigation, her hemoglobin was $10.9 \mathrm{~g} / \mathrm{dl}$, hematocrite $33.7 \%$, white blood cells $10.760 / \mathrm{ml}$, Neutrophiles 70.5\%, C-reactive protein $0.06(<0.5)$, lactate dehydrogenase $322 \mathrm{UI} / \mathrm{L}$ ( 240 - $480 \mathrm{UI} / \mathrm{L}$ ) and serum HCG negative.

The vaginal ultrasound showed a heterogenic mass of $79 \times 67 \times 89 \mathrm{~mm}$ and the presence of important amount of liquid in the Douglas.

An abdominal scan was performed and a mass of $7 \mathrm{~cm}$ and of heterogeneous enhancement, probably of ovarian origin was confirmed.

Exploratory laparoscopy was performed and a four times torsion of the left tube was observed. Initially the surgeons attempted a detorsion in order to evaluate the revascularisation of the tube, however, without success. Following this, a left salpingectomy took place. The opposite ovary was normal.

Macroscopically, the histological piece consisted of the fallopian tube together with blood clots. The microscopic histological examination revealed an atrophic epithelium of the tube. The fallopian wall was extremely congestive, hemorrhagic and inflammatory. Moreover there were found groups of dislocated cells, a finding which could be due to a neoplastic proliferation. "Coffee" bean cells were observed but Call-Exner bodies were not found (Figure 1). The immunohistochemistry of these cells revealed that the anti-calretinin, anti-inhibin, anti-AE1-AE3, anti-CK7 (CK cytokeratin), antiPAX8, anti-CK5.6 (weakly expressed) and anti-RO antibodies were positive. On the contrary the anti-melan-A, 


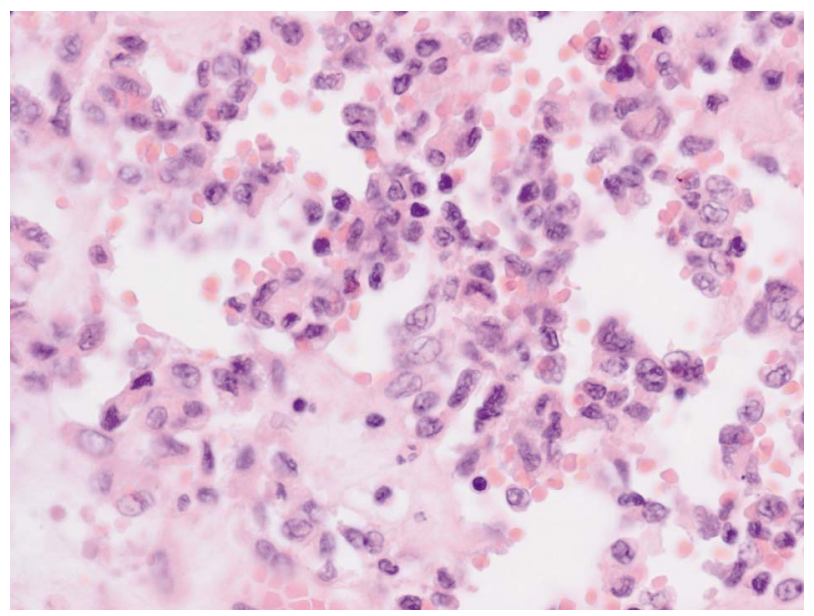

Figure 1. Characteristic coffee bean cells as seen in the histopathological analysis $(\times 400)$.

anti-EMA and anti-HCG antibodies were negative concluding that it was a granulosa cell tumor. The tumor measured $15 \mathrm{~mm}$ deriving from the fimbriae. According to the FIGO classification it was characterized as a FIGO Ia tumor. Given the tumors stage and size we decided not to re-operate but to follow the patient by performing MRI annually.

\section{DISCUSSION}

GCT, an uncommon ovarian cancer, can be of adult or juvenile type based on different clinical and histological features. The more common adult type of GCT usually presents during the perimenopausal or the early menopausal period, the median age being 50 - 54 years.

Rarely, extraovarian GCT can develop. Twelve such cases have so far been reported in the literature. Three cases were reported from India [1-3]. Extraovarian granulosa cell tumors have been reported in retroperitoneum, broad ligament, mesentery, omentum, liver and adrenals [1-9]. Histogenetic origin is thought to be from ectopic gonadal stromal tissue from the mesonephros [2].

The cytological smears of a GCT are usually cellular, the cells being present in loose aggregates, follicular groupings and some in a dispersed fashion. The cells have scanty to moderate pale cytoplasm and monomorphic round to oval nuclei having longitudinal grooves and granular chromatin. The characteristic amorphous globular structures called Call-Exner bodies are present in some GCTs.

A number of tumor markers are used for confirmation of histologic diagnosis of GCT, an important one being inhibin. It has been found to be a more reliable marker for GCT than estradiol. Although an elevated inhibin level may be observed in some epithelial ovarian cancers, these may be confirmed by their EMA (epithelial membrane antigen) positivity, which is negative in GCT. Re- cently, Activin B has been introduced as a new marker for post-operative follow-up of patients with a history of GCT [10].

In our case we found an extra-ovarian GCT due to a fallopian torsion. It is not likely that the torsion was caused by the tumor given its small size $(15 \mathrm{~mm})$.

As far as the surgical treatment is concerned we decided not to re-operate for complete staging given the stage and the size of the tumor and the five-year survival rates which are close to $90 \%$ for a stage I tumor.

Finally, there is no consensus on the follow-up of such patients. Up to now it is proposed that the patient should undergo a pelvic examination and measurement of inhibin levels every three months for the first 2 years, every 4 to 6 months for 3 to 5 years and yearly thereafter. In our case we did not measure the inhibin before the operation since diagnosis was not known and therefore follow-up of inhibin might not be correct. In this case we decided to perform MRI annually.

\section{CONCLUSIONS}

In our case we report an extraovarian granulose cell tumor on the fimbriae of the fallopian tube and it is the first time described. However, the rarity of our publication stands also on the fact that no visible mass was observed at the time of laparoscopy whereas in any other publication a visible and usually big mass was seen. In our case the histological examination reported a mass of $15 \mathrm{~mm}$. Furthermore what is interesting is that in case of revascularization of the tube, a salpingectomy would not have taken place.

\section{REFERENCES}

[1] Naniwadekar, M.R. and Patil, N.J. (2010) Extraovarian granulosa cell tumor of mesentery: A case report. Pathology Research Internation, 4, Article ID 292606.

[2] Paul, P.C., Chakraborty, J., Chakrabarti, S., et al. (2009) Extraovarian granulosa cell tumor. Indian Journal of Pathology and Microbiology, 52, 231-233. doi:10.4103/0377-4929.48928

[3] Reddy, D.B., Rao, D.B. and Sarojini, J.S. (1963) Extraovarian granulosa cell tumor. Journal of the Indian Medical Association, 41, 254-257.

[4] Keitoku, M., Konishi, I., Nanbu, K., et al. (1997) Extraovarian sex cord-stromal tumor: Case report and review of the literature. International Journal of Gynecological Pathology, 16, 180-185. doi:10.1097/00004347-199704000-00017

[5] Kim, S.H., Park, H.J., Linton, J.A., et al. (2001) Extraovarian granulosa cell tumor. Yonsei Medical Journal, 42, 360-363.

[6] Robinson, J.B., Im, D.D., Logan, L., et al. (1999) Extraovarian granulosa cell tumor. Gynecologic Oncology, 74, 123-127. doi:10.1006/gyno.1999.5375 
[7] Vanderstichele, S., Elhage, A., Verbert-Scherrer, A., et al. (1996) Granulosa cell tumors: A case located in the broad ligament of the uterus with normal ovaries. Journal de Gynécologie, Obstétrique et Biologie de la Reproduction, 25, 47-52.

[8] Sakai, Y. (2007) Granulosa cell tumor arising in the wall of mullerian cyst of the broad ligament: Report of a case and immunohistochemical study. Archives of Gynecology and Obstetrics, 275, 145-148. doi:10.1007/s00404-006-0185-4
[9] Orselli, R.C. and Bassler, T.J. (1973) Theca granulose cell tumor arising in adrenal. Cancer, 31, 474-477. doi:10.1002/1097-0142(197302)31:2<474::AID-CNCR2 820310227>3.0.CO;2-R

[10] Vihko, K.K., Blauer, M., Puistola, U., et al. (2003) Activin B in patients with granulosa cell tumours: Serum levels in comparison to inhibin. Acta Obstetricia et Gynecologica Scandinavica, 82, 570-574. doi:10.1034/j.1600-0412.2003.00146.x 